\title{
Impact of socio-economic determinants of demand for health for investment purpose
}

\author{
Albert Opoku Frimpong \\ Department of Economics, Kwame Nkrumah University of Science and Technology, Kumasi, Ghana \\ E-mail: frimpongao@gmail.com
}

\begin{abstract}
Ill-health either results in reduced work capacity or loss of days worked and either of these, ipso facto, results in loss of productivity to firms and society and loss of income to employees. Occupational health and safety practice is about prevention of work related illnesses and protection of workers from physical injury and industrial accidents. However, much of the recent discussions have focused more on prevention of industrial accidents and injury with little attention given to prevention of illnesses related to work. This paper explores this gap. The paper examines the impact of socio-economic factors on the demand for preventive medical services by employees. Primary data was used for the study: Questionnaires were administered and interviews conducted for the collection of the data. Using the convenient sampling method, 400 employees in Kumasi, Ghana, were sampled from the private-formal and informal sectors. Both qualitative and quantitative analyses were carried out. Multivariate analysis using multinomial logistic regression model was employed to estimate the impact of socio-economic factors influencing employees' decision to seek preventive medical services. The study found income, free, and convenient access to medical services statistically significant and impacted positively on the demand for preventive medical services. Stakeholders should pay more attention to these variables when designing and reviewing health programmes that have impact on employees' health investment decisions.
\end{abstract}

Keywords: Health Capital, Preventive Medical Services, Health Investment, Employees.

\section{Introduction}

It has been known from the time of Hippocrates that health is affected by airs, waters, and places; thus, influences which potentially affect individuals exposed to them (Black, 1991). The goods and services produced in an economy, in a simple production function, is a function of two factors: capital and labour, and sometimes a third factor, land, is included (Macinko \& Starfield, 2001). Capital refers to assets such as installations and equipment necessary for producing goods or services; and the second element of the production function, labour, according to Becker (1993) represents the number of person-hours required for the production of the desired good or service. The health status of labour is an important factor because without health labour cannot transform their stock of knowledge and skills into production of goods and services (Xiaoqing, 2005), and the importance of health capital increases as the production becomes increasingly health intensive. Cancelliere et al. (2011) point out that poor health either results in reduced work capacity, called presenteeism, or loss of days worked, called absenteeism. O'Brien (2003) reported that individuals with poor health or with specific health conditions like arthritis, depression or other psychological disorders, or chronic backache, for example, work less and earn less than do people in good health. Chakraborty and Das (2005) argue that absenteeism (and presenteeism) and premature retirement due to ill-health can be reduced and avoided by investment in health.

As a person ages her stock of health depreciates which is, of course, "merely one manifestation of the biological process of aging" (Grossman, 1972a; p. 236). Occupation, however, contributes further to this depreciation, especially the health intensive and unhealthy occupations. Amponsah-Tawiah and Dartey-Baah (2011) estimated that the annual number of industrialised fatal workrelated illnesses and accidents in Ghana were more than two million in 2012. It is estimated that 160 million new cases of workrelated illnesses occur and two million people around the world die each year due to work-related illnesses or injuries and occupational accidents (Neira, 2010). Occupational diseases are diseases that arise out of and in the course of employment. The World Health Organisation (2006) reported that a substantial part of the general morbidity of the population is related to work. However, many people do not even know that their ill-health is work related (TUC Education workbook, 2007): Garcia et al. (2004) conducted a study on employed workers in Castell in Spain and found that $21.1 \%$ of unskilled workers, $17.8 \%$ of skilled workers, and $8.4 \%$ of supervisors said they have no knowledge of their job health risks. Concerning the informal sector, the sector according to Lund and Nicholson (2003), is associated with the creation of employment that is often flexible, precarious, and insecure. Alfers (2009) also points out that most of the informal jobs are not only flexible, precarious, and insecure but are also hazardous and take place in environments which are both unhealthy and unsafe.

Ill-health either results in reduced work capacity or loss of days worked and either of these, ipso facto, results in loss of productivity to firms and society and loss of income to employees. The illhealth employees are the most affected at the event of illness in that there is a high probability that firms will be willing to employ workers with relatively low skills to replace high skilled ill-health personnel. Hence, production continues but the flow of income of the ill-health employee consequently ceases. It is in light of such 
situations the Sixtieth World Health Assembly recommends "research on workers' health needs to be further strengthened... giving it priority in national research programmes and grant schemes..." (WHO, 2007; p. 8). Katsoulakos and Katsoulacos (2007) argue that consideration of Occupational Health and Safety (OHS) practices into national agenda is an important decision not for only the developed countries but also for the developing countries. Occupational health refers to a sound state of the body and mind of workers from illness resulting from the materials, processes, or procedures used in the workplace, whiles occupational safety is the protection of workers from physical injury (Abddllar et al., 2009). Protection of workers from physical injury has received much attention from recent discussions at occupational health and safety practice platforms with prevention of workrelated illnesses receiving little attention. This paper explored this gap. Grossman's (1972a) model puts forward that inputs such as medical services and one's own time are used to produce (good) health to increase the amount of time for production of goods and services. Since the health state of the individual is influenced by factors influencing the demand for these health inputs (Chen et al., 2002), the research question is 'What are the socio-economic factors influencing employees' demand for preventive medical services?' and how do these factors impact on the health investment decisions of employees?' This paper focused on prevention of work-related illnesses through preventive medical services; since regular medical examinations enables early detection of workrelated illnesses and diseases (Ghana Health Service, 2010). Also, the paper investigated the difference in health investment between formal (salaried) and informal (non-salaried) employees, between white-collar and blue-collar employees; and to find out if employees have knowledge about the health risks of their jobs and if the knowledge of the job health risks influences them to invest in their health capital. The remainder of this paper is organised as follows the Literature Review is presented in Section 2; the Study Area and Methodology are described in Sections 3 and 4 respectively; the Empirical Results and Discussion are presented in Section 5; finally, the Conclusion of the study is presented in Section 6 .

\section{Literature review}

According to Grossman's (1972a) model, health is both demanded and produced by individuals and it is demanded for two reasons: as a consumption commodity because individuals derive utility from being healthy and as an investment commodity - which this study restricted attention to - determines the total amount of time available for producing goods or services. With regard to the demand for health as consumption and investment commodities, Frimpong (2014) argues that the poor will tend to demand more health for investment purposes while the rich demand more health for consumption purposes. Thus, he argues, the rich will tend to spend most of their time on consumption of goods and services such as watching football match in a stadium, visiting a museum, or having fun at the beach; with the poor, on the other hand, spend most of their time working to earn more income. According to the model, inputs such as medical services and one's own time are used to produce (good) health which in turn serves as one of many inputs such as plant and one's skills to produce the desired goods or services. The model views health as a capital stock which yields an output of 'healthy days' and the incentive for investing in health is to increase the amount of time for generation of income. The model considers health as a durable good that depreciates; however, by means of investment the stock of health capital can be accumulated by combining, for example, medical services and one's own time to produce new health which counters the effect of the depreciation of the health stock. Cropper (1977) developed two models of investment in health. In the first model, Cropper views the relationship between illness and health capital as random rather than as deterministic. She explains that the individual cannot guarantee that illness will not occur for at every point in time one of two states - ill or not ill - will occur. She argues that the probability of either state occurring depends on the health stock which is determined by investment. This latter statement suggests that illness is as well deterministic since the health stock, which is determined by investment, determines the probability of whether or not illness will occur. This means illness is partly deterministic, and partly random, for Cropper herself points out that the motive for investing in health is to decrease the probability of illness. In the second model, an individual invests in his health through his choice of occupation. According to the model, the extent of exposure to pollutants determines and increases the probability of death. The model puts forward that individuals in unhealthy occupations would have their health stock depreciating faster than that of those in healthy occupations. Thus, if the exposure to pollutants, for example, in one firm is relatively higher than that in another firm, employees in firms with higher exposure to pollutants would have their health stock deteriorating faster than that of those in firms with relatively lower exposure to pollutants, all other things being equal. Similarly, different categories of employees in the same firm with different levels of exposure to pollutants would experience different levels of health deterioration because of different tasks performed by these categories of employees. Laporte and Ferguson's (2007) model looks at two kinds of illness: one that reduces the health stock of the individual by a certain proportion and another which reduces the individual's health stock to a certain level. In the first case, the amount of health stock the individual is left with after the illness strikes depends on how much she had before the illness. The pre-illness health stock determines the rate of recovery after the individual is hit by a certain proportion of illness and puts the individual at the position of reducing the probability of contracting another illness. In the second case, because the health stock of the individual falls to a fixed predetermined level, the pre-illness health stock has no influence on the post-illness health stock. The models point out that pre-illness investment should aim at reducing the probability of illness with post-illness investment focusing on the rate of recovery when illness strikes.

Gilleskie (1998) found that those who experience acute illnesses and chose to seek medical care or to be absent from work for at least once during the illness days were insured and younger and also have higher incomes and sick leave coverage. He found also that higher-income individuals are most likely to be insured which influences them to seek medical services more often than lowerincome individuals who do not have health insurance. He concluded that medical treatment and absence from work, generally, are substitutes in the period of illness, rather than as complement. Chen et al. (2002) found that the health state of the individual is influenced by prices, income, and tastes which are factors influencing the demand for health inputs. These factors, according to the authors, have impact upon the consumption decisions individuals make about health inputs which determine the health state. Thus, the extent to which individuals choose to alter the consumption of health inputs depends on factors such as prices, income, and preferences. For example, all other things held constant, the lower the price of health inputs the higher the demand for them. Also, those with higher income are able to afford quality healthcare than persons with lower income; and the preference of an individual influences him or her to choose, for example, western medicine over herbal medicine. Machnes (2006) sought to determine whether there was a difference in the demand for medical services and supplemental health insurance between the selfemployed and wage-earners in Israel. The study found that income was the main explanatory variable: Individuals with higher income, according to the study, were able to afford also supplemental health insurance. Blue-collar workers, who were found to be low income earners, were found to demand less supplemental insurance than white-collar workers.

A study by Starfield et al. (2005) on the effects of primary care revealed a progressively stronger demonstration that primary care improves health. The study revealed that primary care provides greater access to needed services, greater focus on prevention, and early management of health problems. Using multinomial logistic 
regression model, this paper estimated the impact of socioeconomic determinants of the demand for preventive medical services on employees' decision to access this type of care.

\section{The study area}

Kumasi is the capital of Ashanti Region and the second major city, after Accra, in Ghana. Most of the industries in the Kumasi metropolis are located in the Asokwa-Ahinsan-Kaase industrial area, which is the hub of large-scale formal industries. There are also pockets of other industries dotted all over the metropolis. The private-formal companies selected for this study were Coca Cola Bottling Co. Ltd; a brewery firm producing non-alcoholic beverages; Donyma Steel Complex; and DBS Industries Ltd. Both DBS Industries Ltd and Donyma Steel Complex Ltd are basically producers of steel products; namely, aluminium sheets, binding wire, iron rods, and nails, in the construction industry. With regard to health care provision to workers of these firms, Coca Cola Co. Ltd has a clinic at the worksite to provide health care services to the employees and their dependents. DBS Co. Ltd and Donyma Steel Complex do not have clinic at their worksites, at the time of the study, but the firms pay the medical bills of their workers who visit clinic/hospital in line of duty. DBS Ind. Ltd, at the time of the study, had a medical Doctor who visited the worksite everyday of working hours to attend to workers who would need medical treatment. This type of health care provision is referred to by the study as 'near-clinic'. For the informal sector, the burden of health care provision basically falls on the employees. The mode of payment in the informal sector is daily payment and an employee's income increases with his or her daily output. For this reason an employee in the informal sector can choose to work for longer hours and/or throughout the week. The construction workers sampled from the informal sector for the study were no exception of these.

\section{Methodology}

The population of this study was grouped into two categories: private-formal sector and informal sector. The selection of employees from these two sectors enabled the study to capture those exposed to pollutants and whose jobs are also health intensive. Also, these two sectors enabled the study to make comparison of health investment decisions between salaried (private-formal) and non-salaried (informal) employees. The population of the privateformal sector consisted of workers of Coca Cola Bottling Company Limited, DBS Industries Limited, and Donyma Steel Complex Limited. The medical staff and security personnel of these firms were excluded since their services indirectly enter the companies' production. Construction workers constituted the population from the informal sector. For the private-formal sector, the companies were already divided into three broad departments: the administrative, production, and distribution. The construction workers of the informal sector were also grouped into three departments as in the private-formal sector. These departments constituted the strata from which samples were drawn for the study, using the convenient sampling technique. A total of four hundred (400) workers were sampled for the study with two hundred (200) each from the private-formal and informal sectors. Seventy (70) workers each from Donyma Steel Complex Ltd and DBS Industries Ltd and sixty (60) from Coca Cola Bottling Co. Ltd altogether representing $50 \%$ with the other two hundred (200) workers being construction workers from the informal sector also representing $50 \%$ of the sample size of the study.

The study employed cross-sectional data. Questionnaires were administered and interviews conducted. Questions featured in the questionnaire and interviews were centred on pre-illness health investment decisions of employees including whether they know about their job health risks and whether the knowledge of the job health risks influences them to invest in their health capital. Also, the respondents provided information on their health status (self- rated), income, age, education level, as well as years working with their firms. The collected raw data were edited, encoded, and analysed using stata (version 11) statistical software package. Both qualitative and quantitative analyses were employed. The Multinomial logistic regression model was employed to estimate the effects of socio-economic determinants of the demand for preventive medical services. This regression model was employed because the dependent variable is unordered (Baum, 2006) and observable. Also, multinomial logistic regression model is simple and "parameter estimates are easier to interpret than in some other multinomial models" (Cameron \& Trivedi, 2009; p. 484). According to Cameron and Trivedi (2009), multinomial logit can be used when the explanatory variables do not vary across alternatives called case-specific. The multinomial logit specifies that

$$
\mathrm{P}_{\mathrm{ij}}=\frac{\mathrm{xp}\left(\mathrm{xi}^{\prime} \beta \mathrm{j}\right)}{\sum_{i=1}^{m} \exp \left(\mathrm{xi}^{\prime} \beta \mathrm{j}\right)}, \mathrm{j}=1 \ldots \mathrm{m}
$$

where $x_{i}$ are case-specific explanatory variables. The model ensures that $0<\mathrm{p}_{\mathrm{ij}}<1$ and $\sum_{i=1}^{m} \mathrm{pij}=1$. $\beta_{\mathrm{j}}$ is set to zero to ensure model identification for one of the categories, and interpretation of coefficient is made with respect to that category, called the base category. Put differently, interpretation of multinomial models can be in the same way as interpretation of binary logit model parameters, with comparison made to the base category. Setting the base category to be the first category or one of the categories, the multinomial logistic model is expressed as

$$
\operatorname{Pr}\left(y_{i}=j / y_{i}=j \text { or } 1\right)=\frac{\operatorname{Pr}(y i=j)}{\operatorname{Pr}(y i=j)+\operatorname{Pr}(y i=1)}=\frac{\exp \left(x^{\prime} \beta j\right)}{1+\exp \left(x^{\prime} \beta j\right)}
$$

With $\beta_{\mathrm{j}}=0$ and $\sum_{i=1}^{m} \exp \left(\mathrm{xi}^{\prime} \beta \mathrm{j}\right)$ cancellation in the numerator and denominator, $\beta_{\mathrm{j}}$ can be viewed as parameters of a binary logit model between alternatives $j$ and the base category. Hence a positive coefficient from multinomial logit implies that as the explanatory variable increases, one is more likely to choose alternative $j$ than alternative 1 (the base category). The model considered in this study used preventive medical services as the dependent variable with rarely (thus, once a year) seek preventive care as the base category. The dependent variable (preventive care) was coded $2=$ Often seek preventive care (at least once in every three months), 1 = Sometimes seek preventive care (once in every six months), and $0=$ rarely seek preventive care (once a year). Also, for each of the categorical independent variables, a particular category was used as a reference category (control group) and comparison was made with reference to that control group. For example, with regard to the nature of job category, the administrators group was used as the reference group and the likelihood of the distributors and producers to seek preventive care at least once every three months (often) or once in six months (sometimes) was compared to that of the administrators (the reference/control group); also, a firm with no clinic was used as the reference group and the probability of workers in a firm with near-clinic or a firm with full fledge clinic to often or sometimes seek preventive medical services was compared to that of workers in firms with no clinic.

\section{Results and discussion}

\subsection{Descriptive analysis}

From Table 1.1 below, $90 \%$ of the respondents from the privateformal sector were males with females constituting $10 \%$ while $66 \%$ males and $34 \%$ females were from the informal sector. With regard to the nature of job, the highest percent, $65 \%$, of the sampled employees from the private-formal sector worked at the Production department with $18 \%$ at the Administration section with the majority of the administrators $(52.78 \%)$ being female. The remaining $17 \%$ were from the Distribution section. Both those from the production and distribution sections were all males. 
Table 1.1: Summary Statistics of Variables

\begin{tabular}{lcc}
\hline \multicolumn{1}{l}{ RESPONSE } & \\
\hline VARIABLE & $\begin{array}{c}\text { Private-formal } \\
\text { (Percent) }\end{array}$ & $\begin{array}{c}\text { Informal } \\
\text { (Percent) }\end{array}$ \\
Gender & 90 & 66 \\
Female & 10 & 34 \\
Education level & & \\
Uneducated & 27 & 61 \\
Basic & 13 & 20 \\
Secondary & 39 & 14 \\
Tertiary & 21 & 5 \\
Nature of job & & \\
\hline Administration & 18 & 10 \\
Production & 65 & 83 \\
Distribution & 17 & 7 \\
Source of job health risks knowledge & & 11 \\
Through the employer & 45 & 11 \\
Through coworkers & 4 & 39 \\
Through the media & 14 & 38 \\
Through years of work & 32 & 1 \\
Through research & 5 & 24 \\
When preventive care is sought & & 22 \\
Often (at least once in three months) & 40 & 54 \\
Sometimes (once in every six months) & 35 & \\
Rarely (once a year) & 25 & \\
\hline Source: Field Data, April 2013 & & \\
\hline
\end{tabular}

Source: Field Data, April 2013

Majority (83\%) of the respondents from the informal sector, from Table 1.1 above, worked at the production section out of which $64 \%$ were males and $36 \%$ being females. The distribution section which was basically drivers were all males, and they constituted the lowest percent of 7\%; with the Administration section representing $10 \%$ out of which $62 \%$ were males and $38 \%$ were females. The reason for a low percent of women in both sectors was possibly due to the health intensive nature of the work in the areas selected for the study. All the women respondents from the privateformal sector worked at the Administration department while $88 \%$ of women respondents from the informal sector worked at the Production section. With respect to the knowledge of the job health risks, a higher percent, $44 \%$, from the private-formal sector said they have a good knowledge of the job health risks followed by $23 \%, 15 \%$, and $13 \%$ who indicated they have fair, poor, and very good knowledge respectively with the lowest percent of $5 \%$ being those who said they have excellent knowledge. For the informal sector, of almost equal percents, $32 \%, 29 \%$, and $26 \%$, of the respondents said they have good, fair, and poor knowledge respectively with the remaining $4 \%$ said they have excellent knowledge of the job health risks. From the table, a higher percent, $45 \%$, of the respondents from the private-formal sector indicated that they got to know the health risks of their jobs through their employers, while a higher percent, 39\%, of the informal sector respondents mentioned the media. Also, the study found that majority $(62.25 \%)$ of the sampled respondents indicated that the knowledge of the job health risks influences them to seek preventive medical services, while a lower percent, $37.75 \%$, said the knowledge of the job health risks does not influence them to seek medical treatments.
Concerning how many times preventive care is sought, a higher percent, $40 \%$, of the respondents from the private-formal sector indicated that they often (defined as at least once every three months) seek preventive care, $35 \%$ said sometimes (thus, once in every six months), and the lowest percent, $25 \%$, said rarely (once every year). Also, a higher percent, $43.56 \%$, of blue-collar workers in the private-formal sector said they often seek preventive care, $33.74 \%$ of them said sometimes, while $22.70 \%$ indicated they rarely seek preventive care. However, a higher percent, $40.54 \%$, of the white-collar workers said they sometimes seek preventive care followed by $35.14 \%$ who said rarely with the lowest percent, $24.32 \%$, indicated that they often seek preventive care. The reason for majority of the blue-collar workers to often seek preventive care was probably because their jobs were health intensive and also were exposed to pollutants as compared to the nature of work of the white-collar workers, which was basically 'paper work'. For the respondents in the informal sector, majority (54\%) of them indicated they rarely seek preventive care followed by $24 \%$ who said often with the remaining $22 \%$ indicated they sometimes seek care. Among the blue-collar workers from the informal sector, $53.30 \%$ of them indicated they rarely seek preventive care followed by $24.73 \%$ who said often while $21.98 \%$ of them said sometimes.

With regard to who pays the preventive care bills, the percent of the respondents from the private-formal sector who said their preventive care bills were paid by the employer (59\%) was higher than that of those who said they paid the bills themselves $(38.50 \%)$. However, among the respondents from the informal sector, the percent of those who said they paid for their own medical bills was much higher (73.50\%) than that of those who said the bills were paid by their employers $(23 \%)$. The study found also that a low percent of $2.50 \%$ (5 respondents) from the privateformal sector indicated that their medical bills were paid by health insurance (3 respondents) or family and friends ( 2 respondents); while at the informal sector, a low percent of $3.50 \%$ (7 respondents) said their medical bills were paid by health insurance (4 respondents) or family and friends (3 respondents). Altogether, seven (7) respondents, representing $1.75 \%$, of the total respondents (400) said they used health insurance to access medical services. This low figure could be attributed to the period this study was conducted. The study was carried out within the period when the National Health Insurance Capitation Programme was being piloted, amidst challenges, in the Ashanti region, Ghana. One of the challenges was that in many occasions, most health care providers refused to attend to patients using health insurance on the grounds that the government was not providing them (the service providers) enough funds to run the capitation programme. This situation, perhaps, discouraged the subscribers to access health care with their health insurance cards.

Table 1.2: Descriptive Statistics of Variables

\begin{tabular}{|c|c|c|c|c|c|c|c|}
\hline \multicolumn{2}{|l|}{ Percentage distribution of } & \multicolumn{3}{|c|}{ Health status } & \multicolumn{3}{|c|}{ Medical bills payer } \\
\hline & Excellent & Very Good & Good & Fair & Poor & Employer & Self \\
\hline \multicolumn{8}{|l|}{ Decision to make when sick } \\
\hline Work and no treatment & 13.17 & 23.95 & 37.13 & 16.77 & 8.98 & 31.74 & 64.67 \\
\hline Work and treatment & 13.49 & 39.68 & 31.75 & 9.52 & 5.56 & 61.11 & 35.71 \\
\hline No work and no treatment & 21.28 & 23.4 & 40.43 & 10.64 & 4.26 & 25.53 & 72.13 \\
\hline No work and treatment & 13.33 & 36.67 & 40.00 & 3.33 & 6.67 & 36.67 & 61.67 \\
\hline \multicolumn{8}{|l|}{ Education Level } \\
\hline Uneducated & 13.56 & 24.86 & 39.55 & 12.99 & 9.04 & 31.07 & 66.10 \\
\hline Basic & 10.29 & 26.47 & 36.76 & 17.65 & 8.82 & 36.76 & 58.82 \\
\hline Secondary & 16.19 & 39.05 & 29.52 & 9.52 & 5.71 & 51.76 & 44.76 \\
\hline Tertiary & 18.00 & 40.00 & 38.00 & 4.00 & 0.00 & 58.52 & 39.22 \\
\hline
\end{tabular}

Source: Field Data, April 2013 
From Table 1.2 above, the percent of respondents whose medical bills were paid by the employer increases with higher education from being uneducated $(31.07 \%)$ to having tertiary education (58.52\%). Likewise, the percent of those who paid their own medical bills decreases with higher education. This suggests that medical bills payment coverage by employers is most likely to cover greater number of those with higher education, who are most likely to be white-collar workers. The study again found that, at the event of illness, a small percent of poor health status respondents indicated that they would work with the illness and would not seek medical treatment $(8.98 \%)$ while a higher percent of good health status respondents preferred to work with illness without seeking medical treatment $(37.13 \%)$. Furthermore, the percent of those who pay their own medical bills and prefer to be absent from work to stay home to recuperate without seeking medical care $(72.13 \%)$ was much higher than that of those whose medical bills are paid by the employer and prefer to stay home to recuperate (25.53\%). This is probably because staying home to recuperate has zero monetary cost of medical treatment. Conversely, the percent of those whose medical bills are paid by the employer $(61.11 \%)$ and prefer to go to work when ill and seek medical treatment as well was much higher than that of those who pay their own medical bills $(35.71 \%)$. This is probably because going to work and seek treatment as well is meant to make the illness a "workplace illness" so that the employer would pay the medical bills.

The study found that the percent of those whose medical bills were paid by the employer and also were influenced by the knowledge of the job health risks to seek medical care $(67.68 \%)$ was much higher than that of those who were not influenced by the knowledge of the job health risks to seek care (32.32\%). Also, for those who paid for their own medical bills, the percent of the respondents who were influenced by the knowledge of the job health risks to seek care $(58.48 \%)$ was much higher than that of those who were not influenced by the knowledge of the job health risks to seek care $(41.52 \%)$. This reveals that the percent of those who were influenced by the knowledge of the job health risks to seek care and whose medical bills were paid by the employer $(67.68 \%)$ was higher than the percent of those who paid their own medical bills and were influenced by the knowledge of the job health risks to seek care $(58.48 \%)$. Conversely, the percent of the respondents who indicated that they were not influenced by the knowledge of the job health risks to seek care and happened to pay their medical bills $(41.52 \%)$ were higher than the percent of those whose medical bills were paid by the employer and were not influenced by the knowledge of the job health risks to seek care $(32.32 \%)$. This suggests that in as much as the knowledge of the job health risks influences the respondents to seek medical treatment, the payer of the medical bills is also a relevant factor with respect to health investment decisions. This is because for those who pay their own medical bills, an increase in the knowledge of the job health risks increases their demand for preventive medical services but not as much as when the employer pays the medical bills. Similarly, for those whose medical bills are paid by the employer, an increase in the knowledge of the job health risks increases their demand for preventive care more than when the employees themselves pay for the bills, suggesting that employees tend to increase their demand for preventive medical services if they have 'free' access to medical care. These findings were reflected in the quantitative analysis.

\subsection{Quantitative analysis}

Table 1.3 below shows the results of the multinomial logistic regression model to estimate the effects of socio-economic factors influencing the demand for preventive medical services: Often (seek preventive care at least once every three months), Sometimes (seek preventive care once in six months) or Rarely (seek preventive care once a year). The base category for the model is rarely seeking preventive care. The coefficients of sometimes and often seek preventive care were interpreted with respect to the base category (rarely seek preventive care). The statistical significance of the coefficients estimated is determined by the number of stars as shown by the legend below the table. The model fit is good with pseudo $\mathrm{R}^{2}$ equals 0.135 . Also, overall test of the significance of the model shows that the model is statistically significant at $5 \%$ error level since the model's p-value of 0.00 is less than 0.05 . Therefore the variables in the model jointly have significant impact on the probability that a sampled employee would seek preventive medical services. A positive sign of an estimated coefficient implies increases in that variable tend to increase the demand for preventive care for a particular category: often or sometimes.

At 5\% error level, the model identified some significant variables associated with demand for preventive medical services: Age was found to be statistically significant for often seek preventive care, but the sign was negative which implies the sampled employees were less likely to often seek preventive care for investment purposes as they age, suggesting employees getting close to their retirement would be less likely to often seek preventive care. Income was found to be statistically significant implying income influences the sampled respondents to sometimes or often seek preventive medical services. The positive sign of the coefficient of income implies that with a rise in income, a sampled employee would be most likely to seek preventive care at least once every three months (often) or once in six months (sometimes) than to seek preventive care once a year (rarely), all other factors held constant. This is because health is assumed to be a normal good, hence more is demanded with increase in income. The study found that both the private-formal and informal respondents spent some amount of their income on preventive medical services which included treatments they sought when at home or on weekends. A firm with clinic was also found to be statistically significant influencing the workers to seek preventive medical services either once every three months (often) or once every six months (sometimes). This positive relationship implies that, holding all other factors constant, individuals working in firms with a clinic were most likely to seek preventive care once every three months or once every six months than workers in firms with no clinic. However, a firm with near-clinic was not statistically significant. This suggests that a firm having a near-clinic is not enough to providing convenient access to medical care to its workers. Thus, having a near-clinic is necessary but not sufficient.

The study again found working at the distribution and production departments to be statistically significant to often seek preventive medical services. This positive relationship implies that, holding all other factors constant, workers who work at the distribution or production departments were most likely to seek preventive medical services once every three months (often) than those who work at the administration department. This result is possibly because of the health intensive nature of the work of those in the distribution and production departments and also these workers are often exposed to pollutants. Having a good knowledge of the job health risks was statistically significant to influence the sampled workers to seek preventive care once every three months (often) than having poor knowledge of the health risks of the job. The positive sign implies those with good knowledge of the job health risks were most likely to often seek preventive care than those with poor knowledge of the job health risks, all other factors held constant. Furthermore, the study found those with basic and secondary education to be statistically significant to often seek preventive care, but only having basic education was significant to sometimes seek preventive care. The positive signs of the coefficients of the variables mean those with basic or secondary education were most likely to seek preventive care once every three months than the uneducated; and those with basic education were most likely to seek preventive care once every six months than the uneducated. This is because the educated are most likely to know about the importance of preventive care, hence most likely to seek care. However, having tertiary education was not statistically significant The reason is probably that most of those with tertiary education 
were administrators (white-collar workers) whose demand for preventive medical services was comparatively low because of the low risk nature of their work. Finally, the study found the employer, a proxy for a third party payer, paying for the preventive care bills of employees to be statistically significant to influence the respondents to often seek preventive care. The positive sign of the coefficient implies if the employer pays for the preventive care bills of the employees, the most likely would the employees seek preventive care at least once every three months (often) compared to payment of the bills by the employees themselves, all other factors being equal.

Table 1.3: Results of the Multinomial Logistic Regression Model to Estimate the Effects of Socio-Economic Factors that Influence the Demand For Preventive Care By Employees.

\begin{tabular}{|c|c|c|c|c|c|c|}
\hline & \multicolumn{3}{|c|}{ Sometimes } & \multicolumn{3}{|c|}{ Often } \\
\hline Variables & $\begin{array}{l}\text { Coeffi- } \\
\text { cient }\end{array}$ & $\begin{array}{l}\text { Stan } \\
\text { dard } \\
\text { error }\end{array}$ & $\mathrm{p}$-value & $\begin{array}{l}\text { coeffi- } \\
\text { cient }\end{array}$ & $\begin{array}{l}\text { Stan } \\
\text { dard } \\
\text { error }\end{array}$ & $\begin{array}{l}\mathrm{p}- \\
\text { value }\end{array}$ \\
\hline Age & -0.013 & .017 & 0.458 & $-0.038^{*}$ & .019 & 0.049 \\
\hline Income & $0.003 *$ & .001 & 0.020 & $0.005^{* * * *}$ & .001 & 0.000 \\
\hline \multicolumn{7}{|c|}{ Convenience access to medical care } \\
\hline \multicolumn{7}{|c|}{ A firm with no clinic (Ref.) } \\
\hline $\begin{array}{l}\text { A firm } \\
\text { with near- } \\
\text { clinic }\end{array}$ & -0.432 & .582 & 0.458 & 0.303 & .530 & 0.567 \\
\hline $\begin{array}{l}\text { A firm } \\
\text { with clinic }\end{array}$ & $\begin{array}{l}1.188 * \\
*\end{array}$ & .442 & 0.007 & $1.486^{* *}$ & .450 & 0.001 \\
\hline \multicolumn{7}{|c|}{ Nature of job } \\
\hline \multicolumn{7}{|c|}{$\overline{\text { Administration (Ref.) }}$} \\
\hline $\begin{array}{l}\text { Distribu- } \\
\text { tion }\end{array}$ & 0.386 & .608 & 0.526 & $1.362 *$ & .626 & 0.030 \\
\hline Production & 0.434 & .715 & 0.544 & $1.784 *$ & .700 & 0.013 \\
\hline \multicolumn{7}{|c|}{ Job health risks knowledge } \\
\hline \multicolumn{7}{|l|}{ Poor (Ref.) } \\
\hline Fair & 0.393 & .342 & 0.250 & 0.096 & .382 & 0.801 \\
\hline Good & -0.018 & .354 & 0.959 & $0.867 *$ & .364 & 0.017 \\
\hline Very good & 0.254 & .550 & 0.645 & -0.288 & .521 & 0.580 \\
\hline Excellent & -0.362 & .829 & 0.662 & 0.382 & .718 & 0.595 \\
\hline \multicolumn{7}{|c|}{ Education level } \\
\hline \multicolumn{7}{|c|}{ No education (Ref.) } \\
\hline Basic & $0.739 *$ & .368 & 0.045 & $1.119^{* *}$ & .373 & 0.003 \\
\hline Secondary & 0.266 & .370 & 0.473 & 0.884* & .373 & 0.016 \\
\hline Tertiary & -0.048 & .788 & 0.951 & -0.500 & .878 & 0.571 \\
\hline \multicolumn{7}{|l|}{ Gender } \\
\hline \multicolumn{7}{|c|}{ Female (Ref.) } \\
\hline Male & 0.474 & .355 & 0.182 & -0.161 & .342 & 0.637 \\
\hline \multicolumn{7}{|c|}{ Payer of preventive care bills } \\
\hline \multicolumn{7}{|l|}{ Self (Ref.) } \\
\hline Employer & 0.506 & .336 & 0.133 & $.866 * *$ & .330 & 0.009 \\
\hline
\end{tabular}

Pseudo $\mathrm{R}^{2}=0.1345$, $\mathrm{p}$-value $=0.00 \quad * \mathrm{p}<0.05 ; \quad * * \mathrm{p}<0.01 ; * * * \mathrm{p}<0.001$ Source: Field Data, April 2013

\section{Conclusion}

This paper examined the impact of socio-economic factors on the demand for health for investment purpose; thus demand for health for production of goods and services. The paper found income, free, and convenient access to medical services statistically significant and impacted positively on the demand for preventive medical services. Employers should provide healthcare facilities that provide convenient access to preventive medical services to their employees. Firms' Medical bill payment coverage policies should focus more on blue-collar employees who are most likely to be exposed to high health risks and also are most likely to be low income earners. There should be increased education about the health risks of occupations, especially the risky ones, since it was found that a good knowledge of the job health risks influences employees to invest in their health capital. Employers and the media should be the main channel for this education. Since the paper revealed that income has a positive significant impact on the demand for preventive medical services, stakeholders should en- sure that pro poor health programmes such as, but not limited to, National Health Insurance Scheme be smoothly run for intermittent discontinuation of such programmes discourages individuals subscribed to those programmes from accessing preventive medical care as and when they are supposed to.

\section{Acknowledgement}

This paper is based on a section of the author's MPhil (Economics) thesis submitted to the Department of Economics, Kwame Nkrumah University of Science and Technology, Kumasi, Ghana. The author is grateful to Dr. (Sr.) Eugenia Amporfu for her helpful comments.

\section{References}

[1] Abddllah, N. A. C., Spickett, J. T., Rumchev, K. B. and Dhaliwal, S. (2009), Assessing employees' perception on health and safety man agement in public hospitals. International Review of Business Research Papers, 5(4).

[2] Alfers, L. (2009), Occupational Health \& Safety for informal workers School of Development Studies, University of KwaZulu-Natal, Durban.

[3] Amponsah-Tawiah, K. and Dartey-Baah, K. (2011), Occupational health and safety: Key issues and concerns in Ghana. International Journal of Business and Social Science Vol. 2 No. 14.

[4] Baum, C. F. (2006), an introduction to modern econometrics using stata. Stata Press Publication.

[5] Becker, G. (1993), Human Capital. University of Chicago Press. http://dx.doi.org/10.7208/chicago/9780226041223.001.0001.

[6] Black, D. (1991), Paying for health. Journal of Medical Ethics, Vol. 17, No. 3, pp. 117-123. http://dx.doi.org/10.1136/jme.17.3.117.

[7] Cameron, P. C. and Trivedi, P. K. (2009), Microeconometrics using stata. Stata Press Publication.

[8] Cancelliere, C., Cassidy, J. D., Ammendolia, C., and Côté, P. (2011), Effective at improving presenteeism in workers: a system-atic review and best evidence synthesis of the literature. PMC Jour-nal, 11:395.

[9] Chakraborty, S., and Das, M. (2005), Mortality, Human Capital and Persistent Inequality. Journal of Economic Growth, Vol. 10, No. 2, pp 159-192. http://dx.doi.org/10.1007/s10887-005-1670-5.

[10]Chen, S., Shogren, J. F., Orazem, P. F., and Crocker T. D. (2002), Prices and Health: Identifying the effects of nutrition, exercise, and medication choices on blood pressure. American Journal of Agricultural Economics, Vol. 84, No. 4 (Nov., 2002), pp. 990-1002. http://dx.doi.org/10.1111/1467-8276.00362.

[11]Cropper, M. L. (1977), Health, Investment in Health, and Occupational Choice. Journal of Political Economy, Vol. 85, No. 6.pp. $1273-$ 1294.

Docu-

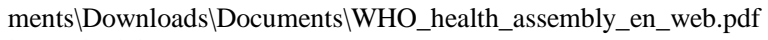
http://dx.doi.org/10.1086/260637.

[12]Frimpong, A. O. (2014), Health as an investment commodity: a theoretical analysis. Journal of Behavioural Economics, Finance, Entrepreneurship, Accounting and Transport, 2014, Vol. 2, No. 3, 58-62.

[13] Garcia, A. M., Boix, P., and Canosa, C. (2004), why do workers behave unsafely at work? Determinants of safe work practices in Industrial workers. Occupational and Environmental Medicine, Vol. 61, No. 3, pp. 239-246.

[14] Ghana Health Services (2010), Occupational Health and Safety Policy Guidelines for the Health http://www.ghanahealthservice.org/publications.php.

[15] Gilleskie, D. B. (1998), a dynamic stochastic model of medical care use and work absence. Econometrica, Vol. 66, No. 1, pp. 1-45. http://dx.doi.org/10.2307/2998539.

[16]Grossman, M. (1972a), On the Concept of Health Capital and the Demand for Health Journal of Political Economy, 80(2): pp. 223-255.

[17]Katsoulakos, T. and Katsoulacos, Y. (2007), Integrating corporate responsibility principles and stakeholder approaches into mainstream strategy: A stakeholder-oriented and integrative strategic management framework. Journal of Technology Management \& Innovation, 7(4) pp. 355-69.

[18]Laporte, A. and Ferguson, B. S. (2007), Investment in health when health is stochastic, Journal of Population Economics, Vol. 20, No. 2. http://dx.doi.org/10.1007/s00148-006-0068-9.

[19]Lund, F. and Nicholson, J. (2003), Chains of production, ladders of protecttion: Social protection for workers in the informal economy. School of Development Studies, University of Natal. 
[20]Machnes, Y. (2006), the demand for private health care under national health insurance: The case of the self-employed. The European Journal of Health Economics, Vol. 7, No. 4, pp. 265-269. http://dx.doi.org/10.1007/s10198-006-0366-x.

[21] Macinko, J. and Starfield, B. (2001), the utility of social capital in research on health determinants. The Milbank Quarterly, Vol. 79, No. 3. http://dx.doi.org/10.1111/1468-0009.00213.

[22]Neira, M. (2010), Healthy workplaces: a model for action for employers, workers, policy makers and practitioners. World Health Organization.

[23]O'Brien E. (2003), Employers' benefits from workers' Health insurance. The Milbank Quarterly, Vol. 81, No. 1. http://dx.doi.org/10.1111/1468-0009.00037.

[24]Starfield, B., Shi, L., and Macinko, J. (2005), Contribution of primary care to health care to health systems and health, The Milbank Quar terly, Vol. 83, No. 3, pp. 457-502. http://dx.doi.org/10.1111/j.14680009.2005.00409.x.

[25]TUC Education workbook for union reps., (2007), Occupational health dealing with the issues. http://www.merpolfed.org.uk/tuc.pdf.

[26]Vistnes, J. P. (1997), Gender differences in days Lost from work due to illness. Industrial and Labor Relations Review, Vol. 50, No. 2 http://dx.doi.org/10.2307/2525088.

[27]World Health Organisation (2006), Declaration of workers health WHO Collaborating Centres of Occupational Health: Stresa, Italy.

[28] World Health Organisation (2007). Workers' health: global plan of action. Sixtieth World Health Assembly, Agenda item 12.13.

[29]Xiaoqing, X. (2005), Investment in physical capital, investment in health and economic growth in China. Investment Management and Financial Innovations, 1/2005. 